\title{
Outcome of manual hemorrhoidopexy in the management
}

\section{of hemorrhoids}

\section{Kumar S, ${ }^{1}$ Kafle P, ${ }^{2}$ Shrestha SJ, ${ }^{3}$ Agrawal S, ${ }^{4}$ Patowary BN ${ }^{5}$}

${ }^{1}$ Resident,MCh.Gastroenterology, ${ }^{2,3,4}$ Residents General Surgery, ${ }^{5}$ Professor and HOD, Department of Surgery, College of Medical Sciences, Bharatpur, Chitwan Nepal.

\section{ABSTRACT \\ Background}

Manual hemorrhoidopexy is a new technique of treating second degree hemorrhoids. In contrast to the conventional resectional techniques (Milligan-Morgan), manual hemorrhoidopexy is a novel technique as described by $\mathrm{T}$ Carlo. It does not involve excision but plication with fixation of the prolapsing hemorrhoid.

\section{Objective}

To study the outcome of manual hemorrhoidopexy and to compare manual hemorrhoidopexy with the traditional hemorrhoidectomy

\section{Methods}

This is a prospective study conducted over 16 months (January 2012 to April 2013) in the College of Medical Sciences Teaching Hospital (COMS-TH), Bharatpur, Chitwan, Department of Surgery. The patients who presented with third degree internal-hemorrhoids on a random basis, and underwent either conventional hemorrhoidectomy (Group A) or Manual hemorrhoidopexy (Group B) by senior consultant surgeons were included. The patients who had external hemorrhoids in addition to internal were excluded. Preoperative, intraoperative, and postoperative characteristics were evaluated.

\section{Results}

Twenty five patients with median age group 42.5 years underwent conventional (Milligan-Morgan) hemorrhoidectomy (Group A) and 25 patients with mean age of 40.1 years underwent manual hemorrhoidopexy (Group B). Male patients were predominant in both groups. The patients in group $A$ had more postoperative pain as compared to group $B$ (as assessed by the visual analogue scale and requirement of post-operative analgesic) and this was statistically significant $(p<0.001)$. There was no significant difference among the other post-operative urinary retention. Twelve percent $(n=3)$ patients in group $A$ had post-operative bleeding and only $4 \%(n=1)$ in group $B$ which was statistically significant $(p<0.001)$. Mean duration of hospital stay in group A was 2.5 days as compared to 1.5 day in group $B$. Median follow up in both the study group was $3(2-4)$ months.

\section{Conclusion}

Manual hemorrhoidopexy has comparable outcomes in term of postoperative analgesic requirement, and post operative complications. 
Journal of College of Medical Sciences-Nepal, 2013, Vol-9, No-2,

\section{INTRODUCTION}

For centuries the human race has been plagued by a very common condition called haemorrhoids. Yet the whole subject is still clouded by misconception and folklore. ${ }^{1}$ It is almost impossible to calculate its prevalence for many patients with haemorrhoids are asymptomatic. So only symptomatic patients with haemorrhoids should be taken into consideration. It is one of the oldest diseases suffered by mankind well recorded in ancient texts of Greeks, Egyptians, Hindus, and Bible. Many great personalities have suffered from haemorrhoids like the Philistines, Napolean Bonaparte, Don Juan Demoranna. It is said Napolean Bonaparte lost his battle of Waterloo because of the delay in launching the attack due to a bad attack of bleeding haemorrhoids. Lewis introduced cryosurgery in treatment of haemorrhoids which was later followed by Frazer and Gill (1967), Lewis et al (1969), Lloyd Willing et al (1973). Neiger introduced photocoagulation in 1979. Most recently laser haemorrhoidectomy has been tried. Longo in 1998 has described stapled haemorrhoidopexy for painless treatment of haemorrhoids. ${ }^{2}$

Treatment of hemorrhoid dated back heralding from band ligartion, sclerotherapy to open hemorrhoidectomy which is considered as Goldstandard treatment .With the advent of new technology human being are craved for more discoveries one after another. In the arena of hemorrhoid treatment a newer technology has been developed recently. We would like to observe the effectiveness of the new technology at our tertiary centre. Here we would like to compare the outcome of conventional open hemorrhoidectomy and the manual hemorrhoidopexy. This study is based on the latest technique described by Dr. Carlo known as manual hemorrhoidopexy. ${ }^{3}$ T. Carlo used "the beak" retractor and vicryl 0 or 00 thread with a very curved and robust needle. Once the engorged and prolapsed hemorrhoidal cushion has been identified, suture applied on the fixed mucosa immediately above and then, without ligating, continued with a running stitch for a further three or four stitches terminating at least one $\mathrm{cm}$ above the dentate line.

\section{METHODS}

\section{Study design and patient selection}

This is a prospective randomized study. It was approved by the ethical committee of College of medical sciences Bharatpur Chitwan, Nepal. This study was conducted over 16 months (January 2012 to April 2013) in College of Medical Sciences Teaching Hospital (COMS-TH), Bharatpur, Chitwan, Department of Surgery. In this study,we classified the study group on the basis of type of procedure performed i.e. the patients who presented with third degree internal hemorrhoids on a random basis, underwent either conventional hemorrhoidectomy was labeled as (Group A) and manual hemorrhoidopexy as (Group B). Both the procedure was undertaken by senior consultant surgeons. The patients who had external hemorrhoids in addition to interal and thrombosed hemorrhoids were excluded from the study. Preoperative, intraoperative, and postoperative characteristics were evaluated. Patient who agreed to participate in the study,signed the written consent.

\section{Surgical Technique}

Anoscope and vicryl 0 or 00 thread with a very curved and robust needle was used in surgical intervention. Once the engorged and prolapsed 
Kumar S et al. Outcome of manual hemorrhoidopexy

hemorrhoidal cushion had been identified, suture applied on the fixed mucosa immediately above and then, without ligating, continued with a running stitch for a further three or four stitches terminating at least one $\mathrm{cm}$ above the dentate line. Ligating the continuous suture produces a lifting of the prolapse and a repositioning of the dentate line, which is brought within the rectum. This fixation is repeated with other sutures on the other dilated and prolapsed hemorrhoidal cushions. In addition to prolapse reduction, the ligation of the continuous sutures tightens and collapses the dilated and bleeding hemorrhoidal veins, which disappears later. After completion, we used finger or a gauze swab introduced into and removed from the anus to verify whether the prolapse has been completely resolved or not. The length of continuous suture is adapted to the extent of the prolapsed. This is illustrated in the figure no. 1

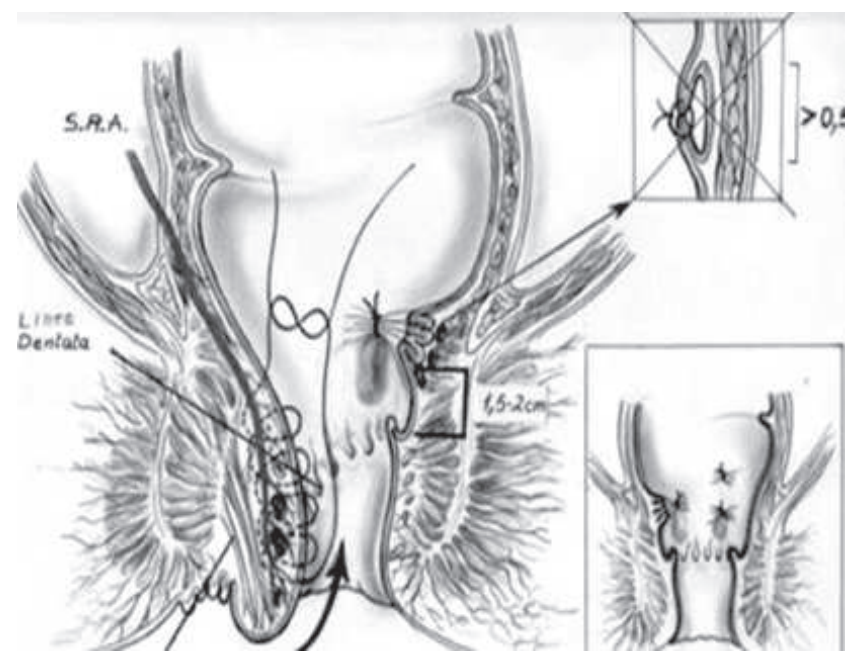

Figure no1: Illustrationof Manual Hemorrhoidopexy.

Post-operatively patients with manual haemorrhoidopexy were started with liquid diet after 6-8 hours of surgery and discharged within 48 hours of surgery with post operative laxative. Post operative antibiotics were prescribed in none of the group. All the data including demographics, operative duration, post operative pain score, requirement of post operative analgesic and postoperative haemorrhoidal symptoms data were analysed using computer base SPSS system. Visual Analogue scale was used to assess the severity of pain,score ranging from 0-10.

\section{RESULT}

Total of 254 cases of hemorrhoid were operated during the study period. Of the total cases, only 50 cases that fulfilled the criteria for the study were included randomly. In both the group there was male preponderance. It was not significant statistically. Mean age of study population in Group A was 42.5 years and 40.1 years in group B. Mean operative time in the group A was 26 minutes for single hemorrhoid followed by 38 minutes for multiple hemorrhoids. Mean operative time for group B was 6 minutes for single hemorrhoid followed by 9 minutes for multiple hemorrhoids. There was minimal bleeding in group A but no bleeding noted in group B. Patient in the group A required post operative analgesia (Injection Diclofenac) in 50\% of the cases up to 24 hours where as the post operative analgesia requirement was minimal in group B. Only $25 \%$ patient required post operative analgesia up to 24 hours. The mean visual analogue score in group A at 12, 24 and 48 hours was 5,4 and 2 respectively where as it was 4, 3 and 1 in group B respectively which was statistically significant $(\mathrm{p}<0.001)$ ). Mean duration of hospital stay in group A was 2.5 days as compared to 1.5 days in group B which is statistically significant $(\mathrm{p}<0.001)$. Post operative per rectal bleeding was noted in 3 patient in group A and one case complained of per rectal bleeding in group B. Post operative urinary retention was 
Journal of College of Medical Sciences-Nepal, 2013, Vol-9, No-2,

the commonest complication observed which was reported as $32 \%$ in group A and $28.5 \%$ in group B which statistically not significant. All the patients in group B were mobilized after 12 hours (24 hours in group A). Prolapsed hemorrhoid was noted in follow up in 2 patients of group A after 4 months and one in the group B. None of the study population complained of sphincter dysfunction in the form of incontinence and tenesmus. None of the study population required the repeat operative procedure within the follow-up period. This is comparable with study conducted by Giordano, et al.where the overall recurrence rate in group A was $9.0 \%$ for prolapse, The summary of the result comparing the outcome in two groups is as tabulated below in Table1

Table1: Outcome of the study comparing open hemorrhoidectomy versus manual hemorrhoidopexy.

\begin{tabular}{l|lll}
\hline Variables & Group A & Group B & P value \\
\hline Male & 16 & 14 & $\mathrm{NS}$ \\
Female & 9 & 11 & $\mathrm{NS}$ \\
Mean age years & 42.5 & 40.1 & $\mathrm{NS}$ \\
Mean operative time minutes & 26 & 6 & $\mathrm{P}<0.001$ \\
Per operative bleeding & Minimal & None & Not quantified \\
\hline Visual analogue score & 5 & & $\mathrm{P}<0.001$ \\
\hline After 12 hours & 4 & 4 & $\mathrm{P}<0.001$ \\
After 24 hours & 2 & 3 & $\mathrm{P}<0.001$ \\
At 48hours & $50 \%$ & 1 & $\mathrm{P}<0.001$ \\
Post operative IM analgesia & & $25 \%$ & \\
\hline Post operative complications & 3 & & $\mathrm{P}<0.001$ \\
\hline Post op per rectal bleeding & 2.5 & 1.5 & $\mathrm{P}<0.001$ \\
Mean hospital stay days & $32 \%$ & $28.5 \%$ & $\mathrm{NS}$ \\
Urinary retention & None & None & $\mathrm{NS}$ \\
Stool incontinence & None & None & $\mathrm{NS}$ \\
Tenesmus & & & \\
NS: not significant. & & & \\
\hline
\end{tabular}

\section{DISCUSSION}

There are very less literature published in the surgical armamenterium on manual hemorrhoidopexy. This is probably the large study after conducting the primary pilot study one year back. First study on manual hemorrhoidopexy was conducted by Tagariello for the first time. Tagariello $^{3}$ Conducted a study on Manual hemorrhoidopexy in the treatment of hemorrhoidal disease from March 2006 to June 2008, 67 patients (36 males; mean age 48.6 years) with grade III hemorrhoids underwent this procedure. There were 
Kumar $S$ et al. Outcome of manual hemorrhoidopexy

no postoperative complications. A total of 61 patients before the operation, reported frequent hemorrhoidal bleeding. The mean postoperative pain measured on a visual analog scale was 1.38. In our study Visual analogue scale was take at different time post operatively at 12, 24 and 48 hours where the mean Visual analogue scale in group A was 5, 4 and 2 respectively where as it was 4, 3 and 1 in group B respectively which was statistically significant $(\mathrm{p}<0.001)$. All patients underwent follow-up for a minimum of 6 months. In 61/67 (91\%) patients, the hemorrhoidal prolapsed was resolved at mean follow-up, whereas in the others the prolapse was reduced to a subjectively acceptable level. In our series, hemorrhoidal prolapsed was seen in one of the case in Group A and none of the case on follow up duration had hemorrhoidal prolapsed in group $\mathrm{B}$. Of the 61 patients who reported bleeding, symptoms in his study, were resolved in 56 $(91.8 \%)$, whereas in the remaining 5 patients there was a reduction in frequency (mean $2 /$ month) and quantity (subjective assessment). In our series, per rectal bleeding was resolved in 22/25 (88\%) in group A and 24/25(96\%) in group B. Prolapsed hemorrhoid was noted in follow up in 2 patients of group A after 2 months and one in the group B after 4 months. This is comparable with study conducted by Giordano et al. ${ }^{4}$ where the overall recurrence rate in hemorrhoidectomy was $9.0 \%$ for prolapsed. His study concluded that the good results can be achieved with Transanal haemorrhoidal dearterialisation with hemorrhoidopexy. Outcome of our series showed that the manual hemorrhoidopexy is comparable to the conventional hemorrhoidectomy in term of mean operating time, post operative pain, post operative hemorrhoidal symptoms and recurrence. It is easy, less time consuming and less invasive.

\section{CONCLUSION}

Restoration of the anal anatomy by mannnual haemorrhoidopexy resulted in a significant improvement in haemorrhoid-associated symptoms and continence. This minimally invasive surgery is comparable to the gold standard open surgery for the hemorrhoid. Further Longterm outcomes needs to be compared with multicentric study with long term follow up.

\section{REFERENCES}

1. Philip H. Gordon, Santhat Nivatvongs. Principles and practice of surgery for colon, rectum and anus, 1 st ed, Quality Medical Publishing Inc., 1992; 1: 10-38.

2. Joseph W. Nunoo- Mensah, Andreas M. Kaiser.Stapled hemorrhoidectomy.Am J Surg. 2005; 190: 1-672.

3. Tagariello C. Manual hemorrhoidopexy in the treatment of hemorrhoidal disease. Surg. 2011; 63:45-50.

4. Giordano P, Overton J, Madeddu G, Zaman S, et al. Transanal hemorrhoidal dearterialization:A Systematic Review. Dis Colon Rectum.2009; 52: 1665-71 